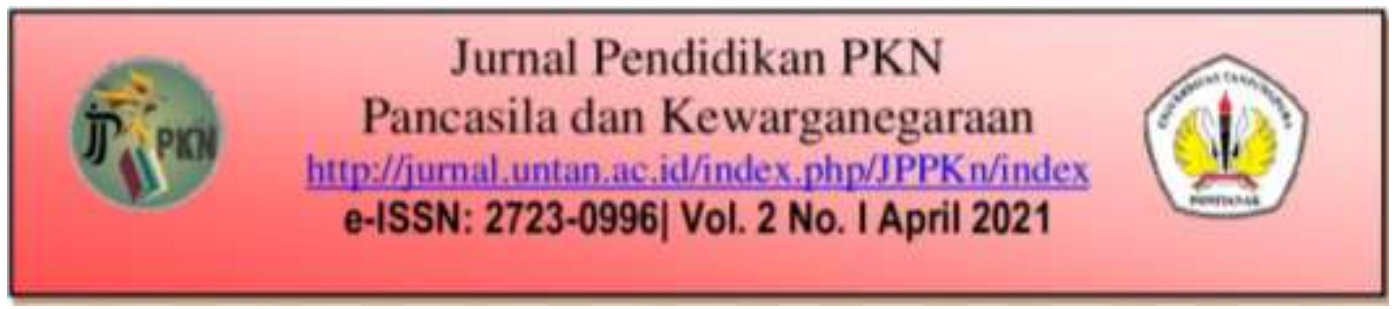

\title{
MODEL PEMBELAJARAN PPKN MELALUI PENDEKATAN KOMPREHENSIF
}

\author{
Intan Kusumawati ${ }^{1}{ }^{*}$, Joko Wahono ${ }^{1}$, Ahmad Nasir Ari Bowo ${ }^{1}$ \\ ${ }^{1}$ Universitas Cokroaminoto Yogyakarta, Indonesia \\ *intankusumawati1978@gmail.com
}

\begin{abstract}
ABSTRAK
Penelitian ini dilatarbelakangi oleh banyaknya permasalahan moral maupun karakter yang dialami khususnya siswa atau generasi muda. Berbagai permasalahan tersebut meliputi kurangnya kedisiplinan, tanggung jawab, nasionalisme peserta didik. Bahkan tidak sedikit juga siswa yang melakukan tindakan kejahatan misalnya tawuran, tindakan kekerasan, penyalahgunaan narkotika dan berbagai permasalahan-permasalahan lainnya. Tentu saja ini menjadi perhatian orang tua dan guru dalam mendidik dan mengantarkan peserta didik agar memiliki karakter yang baik. Tujuan pendidikan pancasila dan kewarganegaraan adalah mencetak generasi bangsa yang berkarakter sesuai dengan nilai-nilai budaya bangsa. Maka dari itu, tugas seorang guru khususnya guru PPKn diantaranya mampu mengembangkan model pembelajaran Pendidikan Pancasila dan Kewarganegaraan (PPKn) yang sesuai dengan karakter siswa agar mempunyai karakter yang baik. Tujuan penelitian ini adalah menemukan sebuah model pembelajaran PPKn yang dapat mengembangkan karakter siswa. Penelitian ini menggunakan pendekatan kuantitatif dan kualitatif dalam pengambilan datanya melalui wawancara dan kuisoner. Hasil penelitian menunjukan bahwa model pembelajaran PPKn berbasis dengan pendekatan komprehensif dapat mengembangkan dan membentuk karakter seorang peserta didik menjadi seorang yang berkarakter meliputi penanaman nilai/ inkulkasi (inculcation), keteladan (modeling), fasilitasi nilai (facilitation), dan pengembangan keterampilan siswa (skill building).
\end{abstract}

Kata Kunci: Penelitian Tindakan Kelas, Pendidikan Kewarganegaraan 


\begin{abstract}
Education aims to educate and create the nation's future generation with character. However, problems like brawls, violence, abuse of narcotics and illegal drugs and promiscuity still occurs among the students. This becomes the concern of parents and teachers in educating and leading students to develop their character. The teacher is obligated to develop Pancasila and Citizenship Education learning model suitable to students in order to have good character. The purpose of this study was to find out Pancasila and Citizenship Education learning model to develop students' character. This study used quantitative and qualitative approaches in collecting data through interviews and questionnaires. The results showed that Pancasila and Citizenship Education Learning model based on character education through comprehensive approach could develop and shape the students' character such as inculcation, modeling, values facilitation, and skill building.
\end{abstract}

Keywords: Model, Learning, Pancasila and Citizenship Education, Aproach, Comprehensive

\title{
PENDAHULUAN
}

Pembelajaran Pendidikan Pancasila dan Kewarganegaraan (PPKn) yang telah dilaksanakan di sekolah yang selama ini pada prinsipnya untuk mewujudkan tujuan pendidikan nasional yaitu mencetak generasi yang cerdas, mandiri, dan berkarakter Pancasila. Undang-Undang Nomor 20 Tahun 2003 pasal 3 tentang Sistem Pendidikan Nasional, disebutkan bahwa tujuan pendidikan nasional adalah untuk mengembangkan potensi peserta didik agar menjadi manusia yang beriman dan bertakwa kepada Tuhan Yang Maha Esa, berakhlak mulia, sehat, berilmu, cakap, kreatif, mandiri, dan menjadi warga negara yang demokratis serta bertanggung jawab. Keberhasilan tujuan pendidikan tersebut sangat dipengaruhi oleh keberhasilan dari pembelajaran di kelas.

Keberhasilan pembelajaran di kelas akan dipengaruhi dengan model pembelajaran yang dipakai dan sebagai acuan guru menyampaikan rencana pembelajaran di kelas sesuai tujuan pendidikan. Sesuai dengan ketentuan pasal 37 Undang-Undang No. 20 tahun 2003 menyatakan bahwa pendidikan kewarganegaraan dimaksudkan untuk membentuk peserta didik menjadi warga negara yang baik, untuk menjadikan bangsa yang berkarakter Pancasilais, sehingga Pendidikan Kewarganegaraan (PKn) merupakan salah satu mata pelajaran yang wajib diajarkan di sekolah menengah atas (Sisdiknas, 2003). PPKn yang berhasil dapat terwujud dalam perilaku keseharian peserta didik yang sesuai dengan nilai-nilai budaya bangsa (Sisdiknas, 2003). Peran pendidikan berupaya 
mencetak generasi penerus bangsa melalui pengembangkan kemampuan berpikir kritis siswa, kemandirian, daya kreativitas serta kemampuan memecahkan permasalahan (Zuchdi, 2019).

Pendidikan Pancasila dan Kewarganegaraan akan membentuk siswa menjadi pribadi yang tanggung, bertanggungjawab dan berkarakter yang mampu mematuhi aturan masyarakat serta menjadi warga negara yang baik(Dewantara et al., 2020). Melalui pendidikan akan mengantar seseorang menjadi warga Negara yang memiliki karakter yang nantinya akan mengantarkan Negara tersebut pada tujuan negaranya (Kusumawati, 2016). Pendidikan bahkan dilaksanakan sedini mungkin agar terjadi proses pembentukan karakter (Kusumawati, 2017). Wawasan serta kesadaran mengenai menjadi warganegara yang baik perlu ditumbuhkembangkan melalui sebuah proses yaitu melalui pendidikan. Misi Pendidikan Pancasila dan Kewarganegaraan bahwa untuk menumbuhkan wawasan serta pengetahuan dalam hal nilai-nilai budaya Indonesia yang luhur serta berwawasan nusantara (Sumarsono, 2005). Dalam pembelajaran PPKn menfasilitasi siswa untuk mengembangkan keterampilan, pengetahuan serta wawasan kebangsaan. Pelajaran PPKn akan membentuk karakter siswa secara menyeluruh dari segi agama, sosial, kultural, bahasa, usia supaya menjadi warganegara yang berkarakter.

Realitas pembelajaran selama ini dapat diketahui bahwa pembelajaran PPKn ternyata belum sepenuhnya mampu mewujudkan tujuan yang diharapkan. Beberapa permasalahan kurang berhasilnya tujuan pembelajaran PPKn antara lain beberapa guru belum memanfaatkan maupun mengembangkan media yang sesuai dengan materi pembelajaran (Sumarsono, 2005), penggunaan strategi maupun pendekatan pembelajaran juga belum maksimal (Sumarsono, 2005), serta model pembelajaran yang digunakan. Kurangnya kemampuan guru dalam pembelajaran PPKn tersebut sehingga berdampak pada karakter peserta didik meliputi kurangnya kedisiplinan, tanggung jawab, bahkan sampai ketindakan kriminal (Nuryati dkk, 2017). Untuk mengatasi berbagai kendala tersebut diantaranya model pembelajaran yang digunakan harus disesuaikan dengan kondisi yang ada sesuai dengan keadaan masing-masing siswa (Sumarsono, 2005). Diperlukan pendekatan yang menyeluruh atau komprehensif. Pendekatan ini mulai dari orientasi, eksplorasi, pendalaman dan penyimpulan (Nucci \& Narváez, 2014), sehingga tujuan pembelajaran dapat tercapai. 
Untuk mengatasi berbagai permasalahan sebagaimana dipaparkan pada uraian di atas maka diperlukan model pembelajaran PPKn melalui pendekatan yang menyeluruh atau komprehensif. Tujuan penelitian ini adalah menemukan model pembelajaran PPKn dengan pendekatan komprehensif. Pendekatan komprehensif meliputi penanaman nilai/ inkulkasi (inculcation), keteladan (modeling), fasilitasi nilai (facilitation),dan pengembangan keterampilan siswa (skill building) (Zuchdi, 2019). Pendekatan komprehensif dalam pendidikan karakter meliputi inkulkasi, pemodelan, fasilitasi nilai dan pengembangan soft skill (Lickona, 1991).

Fokus penelitian ini adalah untuk menemukan model pembelajaran PPKn yang sesuai dengan karakteristik siswa yang disesuaikan dengan tema pembelajaran dengan pendekatan komprehenshif. Tujuan Penelitian ini adalah menemukan suatu model pembelajaran PPKn sesuai dengan tujuan pembelajaran PPKn yaitu mengembangkan potensi siswa, baik pengetahuan serta keterampilan yang mengantarkan menjadi warganegara yang baik dan berkarakter. Pembelajaran PPKn memiliki tujuan nilai-nilai moral yang diharapkan mengandung nilai-nilai moral yang dapat diwujudkan dalam bentuk tingkah laku yang disebut dengan karakter (Apriono, 2009). Pembelajaran PPKn yang terkandung nilai-nilai moral yang diharapkan dapat memberikan pembelajaran mengenai bagaimana pelajar bertingkah laku dalam kehidupan dalam keseharian dan dalam kehidupan bermasyarakat. Pelajar diharapkan mendapatkan pengetahuan dan keterampilan yang dipakai dalam bersosialisasi dalam kehidupan sosialnya. Pasal 1 ayat 19 Undang-Undang Nomor 20 tahun 2003 kurikulum dan perangkat pembelajaran digunakan sebagai pedoman pembelajaran di kelas. Pembelajaran PPKn sesuai dengan kurikulum 2013 diharapkan menyajikan pembelajaran secara konstekstual dan mengkaitkan dengan kondisi yang ada di lapangan (Sisdiknas, 2003). Diperlukan teori dan praktek dalam pengemasan pembelajaran di kelas. Guru PPKn yang kreatif, inovatif dan terbuka serta bisa mengidentifikasi masalah dan jalan agar pelajar bisa menemukan solusi dari setiap permasalahan yang ada.

Pembelajaran PPKn Kurikulum 2013 menggunakan pendekatan ilmiah atau saintifik dalam setiap pembelajarannya (Samsuri, 2011). Dalam pembelajaran PPKn seorang guru dituntut menggunakan metode dan model pengajaran yang tepat agar tujuan pendidikan tercapai. Pembelajaran PPKn diharapkan dapat membentuk warga negara Indonesia yang sesuai dengan karakter dalam dasar negara, yaitu 
Pancasila dan Pembukaan Undang-Undang Dasar tahun 1945 (Ihsan, 2017). Mata pelajaran PPKn dapat mengembangkan moral dan nilai meningkatkan mutu dan kepribadian Indonesia sesuai dengan UndangUndang Sistem Pendidikan Nasional (Syam, 2011). Pendekatan yang dilakukan mulai dari pendahuluan, kegiatan inti dengan mencari dan menemukan, mendalami dan menyimpulkan akhir pembelajaran. Dengan pendekatan komprehensif diharapkan peserta didik atau pelajar dapat memiliki karakter yang diharapkan sesuai dengan tujuan pembelajaran PPKn. Pertanyaan yang ingin dikemukan dalam penelitian ini adalah bagaimana model pembelajaran PPKn yang sesuai untuk diterapkan dalam pembelajaran, serta untuk pengembangan pengetahuan dan keterampilan siswa menjadi warganegara yang baik.

\section{METODE PENELITIAN}

Metode penelitian ini adalah kombinasi antara kuantitatif dan kualitatif yang disebut mixed methods research. Penelitian dengan menggunakan mixed methods research (Cohen et al., 2018: 31) dengan pengumpulan data, analisis dan pencampuran baik data kuantitatif maupun kualitatif. Penelitian ini dilakukan untuk mengetahui pelaksanaan pembelajaran PPKn di sekolah dengan menggunakan pendekatan komprehensif dalam pembelajarannya. Tahapan mixed methods research (Cohen et al., 2018: 48) mulai dari menemukan tujuan penelitian, pertanyaan penelitian, pengumpulan data kuantitatif dan kualitatif, analisis data, dan terakhir membuat laporan penelitian. Penelitian ini menggunakan teknik analisa data secara kualitatif dan juga kuantitatif. Penelitian dengan wawancara serta menggunakan kuisioner dalam pengambilan data melalui instrument penelitian. Subjek penelitian ada 5 sekolah yang ada di Daerah Istimewa Yogyakarta yaitu SMA N 2 Sleman, SMA N 1 Sentolo Kulon Progo, SMA Negeri Patuk Gunung Kidul, SMA N 1 Banguntapan Bantul dan SMA Muhammadiyah 2 Yogyakarta.

\section{HASIL DAN PEMBAHASAN}

Model Pembelajaran PPKn melalui pendekatan komprehensif ini dilakukan peneliti di kelima sekolah yang lokasinya berada di Daerah Istimewa Yogyakarta yang merupakan kota pelajar serta mengedepankan pendidikan melalui visinya yaitu Terwujudnya Peningkatan Kemuliaan Martabat Manusia Jogja dengan memiliki misi Kemuliaan martabat manusia Jogja menyandang Misi "Lima Kemuliaan" atau "Pancamulia", 
yakni : (1) Terwujudnya peningkatan kualitas hidup - kehidupan penghidupan masyarakat yang berkeadilan dan berkeadaban, melalui peningkatan kemampuan dan peningkatan ketrampilan sumberdaya manusia Jogja yang berdaya saing, (2) Terwujudnya peningkatan kualitas dan keragaman kegiatan perekonomi masyarakat, serta penguatan ekonomi yang berbasis pada sumberdaya lokal (keunikan teritori ekonomi) untuk pertumbuhan pendapatan masyarakat sekaligus pertumbuhan ekonomi yang berkeadilan, (3) Terwujudnya peningkatan harmoni kehidupan bersama baik pada lingkup masyarakat maupun pada lingkup birokrasi atas dasar toleransi, tenggang rasa, kesantunan, dan kebersamaan, (4) Terwujudnya tata dan perilaku penyelenggaraan pemerintahan yang demokratis, dan (5) Terwujudnya perilaku bermartabat dari para aparatur sipil penyelenggara pemerintahan atas dasar tegaknya nilai-nilai integritas yang menjunjung tinggi kejujuran, nurani rasa malu, nurani rasa bersalah dan berdosa apabila melakukan penyimpangan-penyimpangan yang berupa korupsi, kolusi, dan nepotisme. Implementasi pendidikan karakter di sekolah tidak merupakan mata pelajaran tersendiri, tidak pula merupakan tambahan standar kompetensi (SK) dan kompetensi dasar (KD), tetapi dapat diintegrasikan ke dalam mata pelajaran yang sudah ada, pengembangan diri, dan budaya sekolah, serta muatan lokal (Judiani, 2010).

Manusia atau seseorang yang mempunyai kepribadian dan karakter apalagi seorang yang terdidik semestinya menjadi orang yang bijak dalam segala aktivitas dalam kehidupannya (Megawangi, 2010). Karakter seseorang akan terus berkembang ketika seseorang itu mau belajar mau berproses dan terus menerus berusaha ke arah pengembangan diri yang baik dan bisa suatu saat kelak menjadi pribadi yang kuat dan berkarakter Pancasila. Namun dalam pembelajaran di sekolah masih terdapat penilaian sikap siswa yang belum terdokumentasi, kurangnya pemahaman guru untuk mengimplementasikan pendidikan karakter, dan tidak adanya sinergi antara pendidikan di sekolah dengan pendidikan di rumah (Darmayanti \& Wibowo, 2014). Zaman telah berubah dengan pesatnya dan mengakibatkan arus globalisasi memberikan dampak positif dan negatif bagi setiap warga negara Indonesia (Kurniawan, 2015). Diperlukan penangan segala bentuk dampak negatif mengenai arus globalisasi dengan membetengi dengan pendidikan karakter (Dalyono \& Lestariningsih, 2016).

Setiap orang seharusnya bertanggungjawab atas karakternya. Pendidikan karakter tidak hanya cukup disampaikan di sekolah saja 
namun semestinya diterapkan dalam kehidupannya sehari-hari (Gunawan, 2012). Baik buruknya karakter seseorang tidaklah hanya dilihat secara pintas saja namun secara menyeluruh. Pendidikan karakter perlu ada penanganan serius dalam berbagai pihak, mulai dari dalam keluarga, sekolah, dan masyarakat. Pendidikan karakter pada prinsipnya adalaha merupakan usaha yang dilakukan secara sadar dan bertanggungjawab dengan hati yang komitmen, jujur, mandiri, ikhlas dan niat dalam hati oleh berbagai personil sekolah baik dari kepala sekolah, guru, karyawan dan murid, bahkan yang dilakukan bersama-sama dengan orang tua dalam kehidupan rumah tangga yang terdiri dari ayah, ibu, kakak dan anggota masyarakat untuk membantu anak-anak dan remaja agar menjadi atau memiliki sifat peduli (Hendriana \& Jacobus, 2017).

Anak berkarakter sehat bukan berarti tak pernah melakukan hal-hal yang negatif, melainkan perilaku itu masih dalam batas wajar (Suwito, 2012). Seorang anak terkadang masih melakukan imitasi atau peniruan dengan orang-orang yang ada disekitarnya. Perilaku anak yang terkadang melakukan kenakalan yang masih wajar masih bisa diperbaiki perilakunya. Dengan teguran atau nasehat yang bijak dan motivasi dari lingkungannya untuk berperilaku baik, sopan dan berkarakter. Individu yang berkarakter baik adalah individu yang dapat membuat keputusan dan siap mempertanggungjawabkan setiap akibat dari keputusannya, dan menjadi individu yang baik dan perlu adanya kesadaran diri yang dilakukan secara sadar (Ramdhani, 2017). Karakter seseorang bisa dikondisikan secara social (Riesman et al., 2020). Secara sosial karena memang kehidupan sosial masyarakatlah yang membentuk karakter seseorang tersebut. Orang yang satu bisa mempengaruhi orang yang lainnya. Sebuah alternatif dari pendidikan karakter adalah etika kepedulian. Etika kepedulian dapat dilihat sebagai pada dasarnya relasional, bukan berbasis individu-agen di jalan etika kebajikan, dan etika kepedulian lebih tidak langsung daripada pendidikan karakter (Noddings, 2002).

Dalam beberapa tahun terakhir "pendidikan karakter" telah muncul di Amerika Serikat sebagai istilah utama untuk upaya sekolah untuk melaksanakan program dalam pendidikan nilai-nilai moral, etika dan kewarganegaraan dan menetapkan 11 prinsip untuk memandu sekolah dalam merencanakan pendidikan karakter mereka. Ini termasuk: isu-isu seperti nilai-nilai etika inti dan pembenarannya, definisi karakter, pendekatan yang komprehensif dan disengaja untuk mengembangkan 
karakter yang baik, mengembangkan sekolah sebagai komunitas yang peduli, hubungan antara pendidikan karakter dan kurikulum akademik serta evaluasi (Lickona, 1996). Padahal pendidikan karakter bukanlah hal baru, namun kajian ilmiah tentang keefektifannya baru dilakukan diterapkan secara sporadis selama tiga puluh lima tahun terakhir. Sebagian besar penerapan oleh karena itu, pendidikan karakter tidak diinformasikan oleh basis pengetahuan ilmiah (Berkowitz \& Bier, 2004).

Pembentukan pendidikan kewarganegaraan sebagai mata pelajaran wajib belakangan ini telah dilakukan dibarengi dengan kebijakan pemerintah untuk 'menggenjot pendidikan berkarakter. Identifikasi memiliki peran penting untuk dimainkan dalam membantu membentuk dan memperkuat karakter dasar (Berkowitz \& Bier, 2004). Pengembangan model pembelajaran ini melalui tiga tahapan yaitu studi pendahuluan yaitu peneliti dan pihak sekolah mendiskusikan rancangan penelitian serta pengalian data yaitu terkaitan pelaksanaan pembelajaran PPKn yang selama ini telah dilakukan, kemudian peneliti bersama guru merancang model pembelajaran PPKn menggunakan cara mengembangkan model berbasis pendidikan karakter dengan menggunakan pendekatan komprehensif. dan setelah itu pengujian model. Dalam penelitian ini didapatkan hasil penelitian sebagai berikut:

Dalam penelitian ini sekolah menggunakan Kurikulum 2013 dalam pelaksanaan pembelajarannya. Kurikulum yang digunakan dengan menggunakan Guide curriculum (kurikulum terbimbing), artinya kurikulum setengah terbuka, setengah tertutup. Rambu-rambu pengajar telah ditentukan dalam kurikulum, tetapi guru masih diberi kemungkinan untuk mengembangkan lebih lanjut dalam kelas. Dalam Pengembangan Kurikulum 2013 di penelitian ini 60\% menekankan pada Keseimbangan pengetahuan, sikap dan ketrampilan. Sedangkan 40\% menggunakan pendekatan saintifik dalam pembelajaran.

Dalam pelaksanaan kurikulum yang dipakai selama ini menggunakan proses pembelajaran aktif, guru melakukan tugasnya sebagai fasilitator maupun motivator dengan mengemas mata pelajaran menjadi lebih maknawi dalam kehidupan sehari-hari dengan model pembelajaran tematik integratif dan pendekatan saintifik. Kelemahan yang terdapat pada kurikulum 2013 adalah cocok diterapkakan di sekolah yang sudah maju dan gurunya semangat belajar tinggi, masyarakat yang sudah terdidik, muridnya memiliki kemampuan dan fasilitas setara serta infrastruktur telekomunikasi dan transportasi sudah merata sehingga 
tidak menghambat proses serta pada penggunaan Ujian Nasional (UN) sebagai evaluasi standar proses pembelajaran siswa aktif.

Model pembelajaran PPKn dalam mengembangkan karakter siswa di kelas dengan menggunakan metode daring dengan menggunakan : (1) Model Pembelajaran Kooperatif. Model pembelajaran kooperatif adalah kegiatan pembelajaran dengan cara berkelompok untuk bekerja sama saling membantu mengkonstruksi konsep, menyelesaikan persoalan atau inkuiri (Purnamasari, 2014); (2) Metode Problem Solving. Model Pembelajaran problem solving adalah sala satu pendekatan yang dalam sebuah pembelajaran kelompok dan membutuhkan kemampuan yang sederhana serta bisa dilakukan oleh semua peserta didik dalam mengemukakan pertanyaan tersebut sesuai dengan materi yang dipelajarinya (Putra, 2018); (3) Metode Pemecahan Masalah. Metode pemecahaman masalah atau Problem Solving sendiri adalah penyajian bahan pelajaran dengan menjadikan masalah sebagai titik tolak pembahasan untuk dianalisis dan disintesis dalam usaha mencari pemecahan atau jawabannya oleh siswa. Di sisi lain, pemecahan masalah juga diartikan sebagai model pembelajaran yang mengajarkan penyelesaian masalah dengan memberikan penekanan pada terselesaikannya suatu masalah secara nalar (Anwar, 2017); (4) Metode Pembiasaan dan Keteladanan. Keteladanan dan pembiasaan dalam pendidikan amat dibutuhkan karena secara psikologis, peserta didik lebih banyak mencontoh prilaku atau sosok figur yang diidolakannya termasuk gurunya. Pembiasaan juga tidak kalah pentingnya dalam kegiatan pembelajaran. Hal ini disebabkan karena setiap pengetahuan atau tingkah laku yang diperoleh dengan pembiasaan sangat sulit mengubah atau menghilangkannya sehingga cara ini amat berguna dalam mendidik (Manan, 2017).

Strategi yang digunakan oleh guru dalam pembelajaran PPKn adalah menggunakan strategi pembelajaran. Strategi Pembelajaran Langsung (instruksi langsung) seperti metode ceramah, pertanyaan didaktik, pengajaran eksplisit, latihan dan latihan, dan demonstrasi. Serta Strategi Pembelajaran Langsung (instruksi langsung) seperti metode ceramah, pertanyaan didaktik, pengajaran eksplisit, latihan dan latihan, dan demonstrasi. Metode pengajaran dalam pembelajaran PPKn yang digunakan guru dalam mengembangkan karakter siswa di kelas dengan pembelajaran interaktif $80 \%$ dan pembelajaran langsung sebanyak $20 \%$, Dalam memberikan tugas belajar kepada siswa dalam pembentukan karakter, guru memberikan tugas berupa belajar mandiri $40 \%$, Belajar 
Kelompok 40\% dan Belajar melalui pengalaman 20\%. Guru dalam memberikan tugas mandiri kepada siswa dalam bentuk karakter bisa dilihat dalam gambar 12 berupa $80 \%$ memberikan pekerjaan rumah dan $20 \%$ melalui pemberian tugas berupa karya tulis. Guru dalam memberikan tugas belajar siswa melalui pengalaman berupa $60 \%$ dengan bermain peran sedangkan $40 \%$ menggunakan observasi atau survey field trips sejumlah $40 \%$.

Dalam memberikan pembelajaran tidak langsung kepada siswa yang berkaitan dengan pengembangan karakter berupa $80 \%$ menggunakan metode pemecahan masalah serta hanya $20 \%$ menggunakan metode studi kasus. Dalam pembelajaran langsung kepada siswa yang berkaitannya dengan pengembangan karakter yaitu dengan menggunakan demontrasi $40 \%$, Pengajaran eksplisit $40 \%$ serta ceramah 20\%. Dalam pembelajaran pada pengembangan karakter siswa berupa diskusi sebanyak $40 \%$, Bermain peran sebanyak $40 \%$, dan Cooperative learning sebanyak $20 \%$, Dalam pengembangan pendidikan karaktter mengedepankan nilai-nilai pengetahuan, ketrampilan sosial dan religiusitas, Komponen karakter yang dikembangkan dalam pembelajaran PPKn di sekolah memuat yaitu komponen moral knowing, moral feeling dan moral action (Dewantara et al., 2020; Triwijaya et al., 2020). Dari hasil penelitian yang dilakukan peneliti pada 5 sekolah yang berada di wilayah Daerah Istimewa Yogyakarta dapat disimpulkan bahwa dalam pengembangan model pembelajaran PPKn selama ini sudah menggunakan pendekatan komprehensif yaitu inkulkasi (inculcatioan), keteladanan (modeling), fasilitasi (facilitation), dan pengembangan keterampilan siswa (skill building).

\section{KESIMPULAN}

Dari hasil penelitian yang dilakukan peneliti pada 5 sekolah yang berada di wilayah Daerah Istimewa Yogyakarta dapat disimpulkan bahwa dalam pengembangan model pembelajaran PPKn selama ini sudah menggunakan pendekatan komprehensif yaitu inkulkasi, pemodelan, fasilitasi nilai dan pengembangan soft skill.

Terimakasih diucapkan kepada Kepala sekolah yang telah memberikan ijin penelitian serta guru dan karyawan SMA N 2 Sleman, SMA N 1 Sentolo Kulon Progo, SMA Negeri Patuk Gunung Kidul, SMA N 1 Banguntapan Bantul dan SMA Muhammadiyah 2 Yogyakarta yang telah bekerjasama dalam kelancaran penelitian ini. Semoga penelitian ini bisa bermanfaat guna pengembangan ilmu pengetahuan dan 
pengembangan keterampilan. Kami juga mengucapkan terima kasih kepada Direktorat Riset dan Pengabdian kepada Masyarakat, Direktorat Jenderal Pemberdayaan Penelitian dan Pengembangan Kementerian Riset Teknologi dan Pendidikan Tinggi (Direktorat Riset dan Pengabdian Masyarakat, Direktorat Jenderal Penguatan Riset dan Pengembangan Kementerian Riset, Teknologi, dan Pendidikan Tinggi Republik Indonesia) atas dukungan dana untuk penelitian dan publikasi artikel ini dengan nomor Hibah 081 / SP2HMAD / LT / DRPM / 2020.

\section{DAFTAR PUSTAKA}

Anwar, N. N. (2017). Meningkatkan pemahaman siswa pada pembelajaran pkn dengan penggunaan metode pemecahan masalah. Syntax Literate; Jurnal Ilmiah Indonesia, 2(3), 99-112.

Apriono, D. (2009). Advance Organizer: Konsep, Komponen Model, dan Imple-mentasi dalam Pembelajaran PPKn. Jurnal Ilmu Pendidikan.

Berkowitz, M. W., \& Bier, M. C. (2004). based character education. The Annals of the American Academy of Political and Social Science, 591(1), 7285.

Cohen, L., Lawrence, M., \& Morrison, K. (2018). Research Methods in Education. Eighth Edition. In Research Methods in Education.

Dalyono, B., \& Lestariningsih, E. D. (2016). Implementasi penguatan pendidikan karakter di sekolah. Bangun Rekaprima: Majalah Ilmiah Pengembangan Rekayasa, Sosial Dan Humaniora, 3(2, Oktober), 33-42.

Darmayanti, S. E., \& Wibowo, U. B. (2014). Evaluasi program pendidikan karakter di sekolah dasar Kabupaten Kulon Progo. Jurnal Prima Edukasia, 2(2), 223-234.

Dewantara, J. A., Efriani, E., \& Sulistyarini, S. (2020). Caring National Identity Through Teacher Contributions in the Border: Pancasila Actionistic Basic Implementation. Jurnal Basicedu, 4(3), 649-661. https://doi.org/10.31004/basicedu.v4i3.407

Gunawan, H. (2012). Pendidikan karakter. Bandung: Alfabeta, 2.

Hendriana, E. C., \& Jacobus, A. (2017). Implementasi pendidikan karakter di sekolah melalui keteladanan dan pembiasaan. JPDI (Jurnal Pendidikan Dasar Indonesia), 1(2), 25-29.

Ihsan, I. (2017). Kecenderungan Global dalam Proses Pembelajaran Pendidikan Pancasila dan Kewarganegaraan di Sekolah. JPK (Jurnal 
Pancasila Dan Kewarganegaraan), 2(2), 49-58.

Judiani, S. (2010). Implementasi pendidikan karakter di sekolah dasar melalui penguatan pelaksanaan kurikulum. Jurnal Pendidikan Dan Kebudayaan, 16(9), 280-289.

Kurniawan, M. I. (2015). Tri pusat pendidikan sebagai sarana pendidikan karakter anak sekolah dasar. PEDAGOGIA: Jurnal Pendidikan, 4(1), 4149.

Kusumawati, I. (2016). Landasan Filosofis Pengembangan Karakter Dalam Pembentukan Karakter. Academy of Education Journal, 7(1), 1-15. https://doi.org/10.47200/aoej.v7i1.342

Kusumawati, I. (2017). Pengembangan Karakter Siswa Raudlatul Athfal Berbasis Pendidikan Agama Islam. As-Sibyan: Jurnal Pendidikan Anak Usia Dini, 1(02), 139-148.

Lickona, T. (1991). Educating for character (New York, Bantam). McCI ET NAN, BE (1992) Schools and the Shaping of Character: Moral Education in America, 525-543.

Lickona, T. (1996). Eleven principles of effective character education. Journal of Moral Education, 25(1), 93-100.

Manan, S. (2017). Pembinaan Akhlak Mulia Melalui Keteladanan dan Pembiasaan. Jurnal Pendidikan Agama Islam-Ta'lim, 2(1), 49-65.

Megawangi, R. (2010). Pengembangan program pendidikan karakter di sekolah: pengalaman sekolah karakter. Jakarta: Indonesia Heritage Foundation (IHF).

Noddings, N. (2002). Educating moral people: A caring alternative to character education. ERIC.

Nucci, L., \& Narváez, D. (2014). Handbook of moral and character education. Routledge.

Purnamasari, Y. (2014). Pengaruh model pembelajaran kooperatif tipe teams games tournament (TGT) terhadap kemandirian belajar dan peningkatan kemampuan penalaran dan koneksi matematik peserta didik SMPN 1 kota Tasikmalaya. Jurnal Pendidikan Dan Keguruan, 1(1), 209664.

Putra, N. L. J. (2018). Upaya Meningkatkan Prestasi Belajar PKn pada Materi Sikap Positif terhadap Norma melalui Model Pembelajaran Problem Solving. Jurnal Ilmu Pendidikan (JIP) STKIP Kusuma Negara, 
9(2), 49-64.

Ramdhani, M. A. (2017). Lingkungan pendidikan dalam implementasi pendidikan karakter. Jurnal Pendidikan UNIGA, 8(1), 28-37.

Riesman, D., Glazer, N., \& Denney, R. (2020). The lonely crowd: A study of the changing American character. Veritas Paperbacks.

Samsuri, S. (2011). Kebijakan Pendidikan Kewarganegaraan Era Reformasi di Indonesia. Cakrawala Pendidikan, 2, 78213.

Sisdiknas, U.-U. (2003). Undang-Undang RI No. 20 Tahun 2003. Jakarta: Sinar Grafika.

Sumarsono, S. (2005). Dkk. In Pendidikan Kewarganegaraan. Jakarta: Gramedia Pustaka Utama.

Suwito, A. (2012). Integrasi Nilai Pendidikan Karakter ke dalam Mata Pelajaran Pendidikan Kewarganegaraan di Sekolah Melalui RPP. CIVIS, 2(2/Juli).

Syam, N. (2011). Peningkatan Kualitas Pembelajaran Pkn di Sekolah Dasar melalui Model Pengajaran Bermain Peran. Perspektif Ilmu Pendidikan, $24(\mathrm{XV})$.

Triwijaya, A. F., Fajrin, Y. A., \& Wibowo, A. P. (2020). Quo Vadis:

Pancasila Sebagai Jiwa Hukum Indonesia. Jurnal Pendidikan PKN

(Pancasila Dan Kewarganegaraan), 1(2), 115.

https://doi.org/10.26418/jppkn.v1i2.41083

Zuchdi, D. (2019). Humanisasi pendidikan. Bumi Aksara. 